Dhaka Univ. J. Biol. Sci. 27(1): 85-92, 2018 (January)

\title{
SCREENING OF SCLEROTINIA STEM ROT RESISTANCE IN BANGLADESH MUSTARD GERMPLASM USING COTYLEDON ASSAY METHOD
}

\author{
Najmun Naher ${ }^{1 *}$, Shamim Shamsi, Md Rawshan Ali² and Md Abul Bashar \\ Department of Botany, University of Dhaka, Dhaka-1000, Bangladesh
}

Key words: Sclerotinia sclerotiorum, Cotyledon, Germplasm, Mustard, Screening

\begin{abstract}
In the present investigation Brassica germplasm were screened in vitro against Sclerotinia sclerotiorum, the causal organism of stem rot disease of mustard (Brassica spp.) using cotyledon assay. The germplasm belong to Brassica rapa, B. juncea, B napus and Brassica sp. Among the 81 germplasm and seven cultivated varieties seven genotypes, namely BD 10113, BD 6948, BD 6954, BD 7108, BD7121, BD 7788 and BD7799 exhibited resistant reaction and eight germplasm viz. JBC 05117, BD 10456, BD6974, BD7116, BD7802, BD7804, BD7806, and BD7807 expressed moderately resistant reaction against $S$. sclerotiorum. The rest 66 germplasm and showed susceptibility at varied degree. Moderately susceptible reaction was observed in 29 , susceptible in 26 and highly susceptible reaction was found in 11 germplasm. Out of seven cultivated varieties three were found highly susceptible, two were susceptible and two showed moderately susceptible.
\end{abstract}

\section{Introduction}

Stem rot in oilseed rape (Brassica napus L.) caused by Sclerotinia sclerotiorum is one of the most devastating fungal diseases worldwide. Sclerotinia sclerotiorum (Lib.) de Bary is a necrotrophic and non-host-specific fungal pathogen that infects more than 400 plant species, including several important oil crops such as oilseed rape, soybean and sunflower ${ }^{(1)}$. It is a serious threat to oilseed rape production with substantial yield losses worldwide including Australia, Europe and North America ${ }^{(2-4)}$. The pathogen is recognized by the fluffy white mycelium and black sclerotia that develops on the surface of lesions ${ }^{(5)}$. Various methods such as cultural, chemical and varietal resistance are used tomanage S. sclerotiorum ${ }^{(6)}$.

Host resistance selection is the only economic and sustainable way of managing this disease $^{(7)}$. Garg et al. ${ }^{\left({ }^{8}\right)}$ reported cotyledon assay in B. napus to rapidly differentiate the genotypes against $S$. sclerotiorum. Most common inoculation technique is myceliainfested substrate (agar plug, carrot, celery and oat) instead of ascospores. Ascosporesare

*Author for correspondence: <najmunsmriti@gmail.com>. ${ }^{1}$ Department of Botany, Life and Earth Science Group, National University, Gazipur-1704, Bangladesh. ${ }^{2}$ Bangladesh Agricultural Research Institute (BARI), Gazipur- 1701, Bangladesh. 
difficult to operate and to produce in vitro, and inoculation with ascospores in laboratory and greenhouse environments ${ }^{(9)}$. Cotyledon test has been used by some researchers to identify resistance to $S$. sclerotiorum in genotypes of soybean ${ }^{(10-11)}$. Identify the resistant sources is one of the best long-term prospect for improved management of this disease. Keeping all these in view, the present investigation was undertaken to examine the reaction of 88 mustard germplasm of Bangladesh against $S$. sclerotiorum using cotyledon assay method.

\section{Materials and Methods}

A single isolate of Sclerotinia sclerotiorum was selected based on aggressiveness reactions on mustard hosts. This isolate was collected from Joypurhat to evaluate the responses of different genotypes of mustard to S. sclerotiorum in greenhouse. Eighty eight germplasm of mustard belongs to Brassica rapa, B. juncea, B. napus and Brassica sp. were selected for screening. Among them 30 germplasm belong to B. rapa, 21 were B. juncea, 32 were $B$. napus and 5 were of Brassica sp. All the germplasm were grown in small plastic pots separately. Five seeds of each genotype were sown in each pot. This experiment was conducted under controlled environment growth room conditions of $20 \pm 1^{\circ} \mathrm{C}$ during the day and $18 \pm 1^{\circ} \mathrm{C}$ at night. Seedlings were grown until cotyledons were fully expanded.

Fifteen isolates of S. sclerotiorum were collected from five districts (Bogra, Jamalpur, Habiganj, Joypurhat and Kusta) of different agro-ecological zones in Bangladesh. One isolate of S. sclerotiorum was selected based on aggressiveness reactions on mustard leaf of BARIsorisa 14.

The selected aggressive isolate of $S$. sclerotiorum was grown on potato dextrose agar (PDA) medium at $20 \pm 1^{\circ} \mathrm{C}$ in an incubator. Seven agar discs (each $5 \mathrm{~mm}$ in diameter) were cut from the actively growing margin of a 3 day old cultured plate of the fungus and transferred to a $250 \mathrm{ml}$ flask containing $75 \mathrm{ml}$ of a sterilized potato dextrose broth. The flasks were incubated at $20 \pm 1^{\circ} \mathrm{C}$ for 5 days. After 5 days, colonies of $S$. sclerotiorum was harvested and washed twice with sterilized water. The fungal mats obtained were transferred to $200 \mathrm{ml}$ of same liquid medium and mycelia were macerated in a food grinder for $3 \mathrm{~min}$. The macerated mycelial suspension was filtered through four layers of cheese cloth and the concentration was adjusted to $10^{4}$ fragments $/ \mathrm{ml}$ using hemocytometer with the same liquid medium.

Twelve days old cotyledons were inoculated with mycelial suspension. A total of two droplets of mycelial suspension of $10 \mu \mathrm{l}$ were deposited on every seedling using a micropipette, with a single drop on each cotyledon. While inoculating, the mycelial suspension in conical flaks are shaken regularly to maintain homogenous mixture. After inoculation all pots were covered with polyethen sheet to maintain $100 \%$ relative humidity. In addition, a very fine mist of water was sprayed over cotyledons and the pot. 
Necrotic and water soaked lesions appeared after two days of inoculation. At 4 days after inoculation, polyethen sheets were removed and lesions were assessed on the basis of lesion diameter (mm). Lesion diameters were measured using a liner ruler. Disease reaction was also measured by revised rating scale (slightly modified) of AICRP rapeseed-mustard ${ }^{(12)}$.

\begin{tabular}{cll}
\hline Rating score & Lesion length $(\mathrm{mm})$ & Disease reaction \\
\hline 0 & No lesion & Immune (I) \\
1 & $0.1-2$ & Resistant (R) \\
2 & $2.1-4$ & Moderately resistant (MR) \\
3 & $4.1-6$ & Moderately susceptible (MS) \\
4 & $6.1-8$ & Susceptible (S) \\
5 & 8.1 and above & Highly susceptible (HS) \\
\hline
\end{tabular}

\section{Results and Discussion}

Cotyledons inoculated with Sclerotinia sclerotiorum showed necrotic and black colored lesions after 4 days of inoculation (Table 1). Typical necrotic lesions appeared on cotyledons of susceptible germplasm. The type, size and severity of lesions on cotyledons varied between the germplasm ranging from very small to extreme (0.5 to $11 \mathrm{~mm}$ ) where entire cotyledons collapsed and were covered with white cottony mycelial growth.

The initial disease symptoms were produced on $24 \mathrm{hrs}$ after inoculating the cotyledon with the isolate of Joypurhat (Fig. 1). After five days whole cotyledon was covered with mycelium of S. sclerotiorum. Seven germplasm, namely BD 10113, BD 6948, BD 6954, BD 7108, BD 7121, BD 7788 and BD 7799 showed resistant reaction and eight germplasm viz. JBC 05117, BD 10456, BD 6974, BD 7116, BD 7802, BD 7804, BD 7806, and BD 7807 were moderately resistant. Moderately resistant germplasm showed a small lesion confined to the size of the inoculum droplet and resistant genotype showed only very small necrotic dots in the inoculation areas. Out of 81 germplasm, 11 were highly susceptible and 26 were susceptible against S. sclerotiorum. The remaining 29 showed moderately susceptible reaction. Out of seven cultivated varieties, three were highly susceptible, two were susceptible and two moderately susceptible. Resistance screening of 81 germplasm revealed that the resistance and susceptible genotypes were easily distinguished by comparing with susceptible varieties of mustard. It was observed that out of 30 Brassica rapa germplasm 2 were resistant, 3 were moderately resistant, 9 were moderately susceptible, 9 were susceptible and 7 were highly susceptible. Out of 21 germplasm of $B$. juncea 3 were resistant, 1 was moderately resistant, 8 were moderately susceptible, 4 were susceptible and 5 were highly susceptible. Out of 32 germplasm of $B$. napus 2 were resistant, 4 were moderately resistant, 12 were moderately susceptible, 13 
Table 1. Screening of 88 Brassica grmplasm against Sclerotinia sclerotiorum.

\begin{tabular}{|c|c|c|c|c|c|c|c|c|c|}
\hline $\begin{array}{l}\text { Sl. } \\
\text { No }\end{array}$ & $\begin{array}{l}\text { Accession } \\
\text { No. }\end{array}$ & Species & $\begin{array}{l}\text { Lesion } \\
\text { length } \\
(\mathrm{mm})^{*}\end{array}$ & $\begin{array}{l}\text { Disease } \\
\text { Reaction }\end{array}$ & $\begin{array}{l}\text { Sl. } \\
\text { No. }\end{array}$ & $\begin{array}{l}\text { Accession } \\
\text { No. }\end{array}$ & Species & $\begin{array}{l}\text { Lesion } \\
\text { length } \\
(\mathrm{mm})^{*}\end{array}$ & $\begin{array}{l}\text { Disease } \\
\text { reaction }\end{array}$ \\
\hline 1. & JBC 05117 & B. rapa & 3.2 & MR & 23. & BD 10115 & B. rapa & 4.5 & MS \\
\hline 2. & JUN 536 & B. juncea & 9.3 & HS & 24. & BD 10455 & B. napus & 7.8 & $S$ \\
\hline 3. & Nap 0564 & B. napus & 5.0 & MS & 25. & BD10456 & B. rapa & 2.4 & MR \\
\hline 4. & BARI sorisa 16 & B. juncea & 6.5 & $\mathrm{~S}$ & 26. & BD 6948 & B. juncea & 1.5 & $\mathrm{R}$ \\
\hline 5. & BARI sorisa 12 & B. rapa & 8.4 & HS & 27. & BD 6949 & B. rapa & 5.5 & MS \\
\hline 6. & BARI sorisa 10 & B. juncea & 11 & HS & 28. & BD 6952 & B. rapa & 5.5 & MS \\
\hline 7. & Tori 7 & B. rapa & 5.5 & MS & 29. & BD 6953 & B. rapa & 9.5 & HS \\
\hline 8. & BARI sorisa 11 & B. juncea & 5.3 & MS & 30. & BD 6954 & B. rapa & 1.8 & $\mathrm{R}$ \\
\hline 9. & Nap 0567 & B. napus & 7.0 & $S$ & 31. & BD 6955 & B. rapa & 6.8 & $S$ \\
\hline 10. & Sau 01 & B. napus & 7.3 & S & 32. & BD 6956 & B. rapa & 4.4 & MS \\
\hline 11. & BARI sorisa 08 & B. napus & 6.6 & S & 33. & BD 6957 & B. juncea & 6.6 & $S$ \\
\hline 12. & BD 9869 & B. napus & 5.3 & MS & 34. & BD 6958 & B. rapa & 4.1 & MS \\
\hline 13. & BD 10105 & B. napus & 5.0 & MS & 35. & BD 6974 & B. juncea & 2.5 & MR \\
\hline 14. & BD 10106 & B. napus & 4.6 & MS & 36. & BD 7104 & B. juncea & 5.5 & MS \\
\hline 15. & BD 10107 & B. napus & 5.6 & MS & 37. & BD 7106 & B. juncea & 6.9 & $S$ \\
\hline 16. & BD 10108 & B. rapa & 7.5 & $\mathrm{~S}$ & 38. & BD 7108 & B. juncea & 0.5 & $\mathrm{R}$ \\
\hline 17. & BD 10109 & B. rapa & 6.6 & $S$ & 39. & BD 7112 & B. juncea & 8.5 & HS \\
\hline 18. & BD 10110 & B. rapa & 4.1 & MS & 40. & BD 7113 & B. rapa & 9.6 & HS \\
\hline 19. & BD 10111 & B. napus & 7.8 & $\mathrm{~S}$ & 41. & BD 7114 & B. rapa & 10.5 & HS \\
\hline 20. & BD 10112 & B. napus & 8.6 & HS & 42. & BD 7115 & B. rapa & 12 & HS \\
\hline 21. & BD 10113 & B. rapa & 0.5 & $\mathrm{R}$ & 43. & BD 7116 & B. rapa & 2.5 & MR \\
\hline 22. & BD 10114 & B. juncea & 5.5 & MS & 44. & BD- 7118 & B. rapa & 5.5 & MS \\
\hline
\end{tabular}

(Contd.) 
(Contd.)

\begin{tabular}{|c|c|c|c|c|c|c|c|c|c|}
\hline $\begin{array}{l}\text { Sl. } \\
\text { No. }\end{array}$ & $\begin{array}{l}\text { Accession } \\
\text { No. }\end{array}$ & Species & $\begin{array}{l}\text { Lesion } \\
\text { length } \\
(\mathrm{mm})^{*}\end{array}$ & $\begin{array}{l}\text { Disease } \\
\text { reaction }\end{array}$ & $\begin{array}{l}\text { Sl. } \\
\text { No. }\end{array}$ & $\begin{array}{l}\text { Accession } \\
\text { No. }\end{array}$ & Species & $\begin{array}{l}\text { Lesion } \\
\text { length } \\
(\mathrm{mm})^{*}\end{array}$ & $\begin{array}{l}\text { Disease } \\
\text { reaction }\end{array}$ \\
\hline 45. & BD 7119 & B. juncea & 4.5 & MS & 67. & BD 7803 & B. napus & 5.6 & MS \\
\hline 46. & BD 7120 & B. napus & 6.5 & S & 68. & BD 7804 & B. napus & 2.6 & MR \\
\hline 47. & BD 7121 & B. juncea & 1.2 & $\mathrm{R}$ & 69. & BD 7805 & B. napus & 4.3 & MS \\
\hline 48. & BD 7127 & B. rapa & 7.7 & $S$ & 70. & BD 7806 & B. napus & 3.5 & MR \\
\hline 49. & BD 7129 & B. juncea & 5.6 & MS & 71. & BD 7807 & B. napus & 2.5 & MR \\
\hline 50. & BD 7131 & B. juncea & 5.3 & MS & 72. & BD 9344 & Brassica sp. & 7.0 & $S$ \\
\hline 51. & BD 7132 & B. juncea & 5.0 & MS & 73. & BD 9346 & Brassica sp. & 7.5 & S \\
\hline 52. & BD 7133 & B. juncea & 8.0 & S & 74. & BD 9347 & Brassica sp. & 5.5 & MS \\
\hline 53. & BD 7134 & B. juncea & 8.5 & HS & 75. & BD 9348 & B. rapa & 8.0 & $\mathrm{~S}$ \\
\hline 54. & BD 7135 & B. juncea & 10 & HS & 76. & BD 9351 & B. rapa & 4.5 & MS \\
\hline 55. & BD 7136 & B. juncea & 4.3 & MS & 77. & BD 9352 & Brassica sp. & 5.0 & MS \\
\hline 56. & BD 7137 & B. napus & 7.5 & $S$ & 78. & BD 9353 & B. rapa & 10 & HS \\
\hline 57. & BD 7724 & B. napus & 6.5 & $S$ & 79. & BD 9354 & B. rapa & 7.5 & $\mathrm{~S}$ \\
\hline 58. & BD 7788 & B. napus & 1.8 & $\mathrm{R}$ & 80. & BD 9355 & Brassica sp. & 8.4 & HS \\
\hline 59. & BD 7790 & B. napus & 6.2 & $S$ & 81. & BD 9864 & B. napus & 6.3 & $S$ \\
\hline 60. & BD 7791 & B. napus & 6.6 & $S$ & 82. & BD 9865 & B. napus & 4.6 & MS \\
\hline 61. & BD 7792 & B. napus & 7.0 & $S$ & 83. & BD 9866 & B. napus & 4.5 & MS \\
\hline 62. & BD 7793 & B. napus & 7.5 & $S$ & 84. & BD 9867 & B. napus & 5.6 & MS \\
\hline 63. & BD 7795 & B. napus & 5.6 & MS & 85. & BD 9868 & B. rapa & 7.3 & $\mathrm{~S}$ \\
\hline 64. & BD 7796 & B. napus & 5.0 & MS & 86. & BARI sorisa 14 & B. rapa & 8.5 & HS \\
\hline 65. & BD 7799 & B. napus & 0.5 & $\mathrm{R}$ & 87. & BD 9343 & B. rapa & 6.0 & $\mathrm{~S}$ \\
\hline 66. & BD 7802 & B. napus & 3.3 & MR & 88. & BD 9348 & B. rapa & 6.5 & $\mathrm{~S}$ \\
\hline
\end{tabular}

*= Average value, $\mathrm{n}=6 ; \mathrm{R}=$ Resistant, $\mathrm{MR}=$ Moderately resistant, MS = Moderately susceptible, $\mathrm{S}=$ Susceptible and HS = Highly susceptible. 

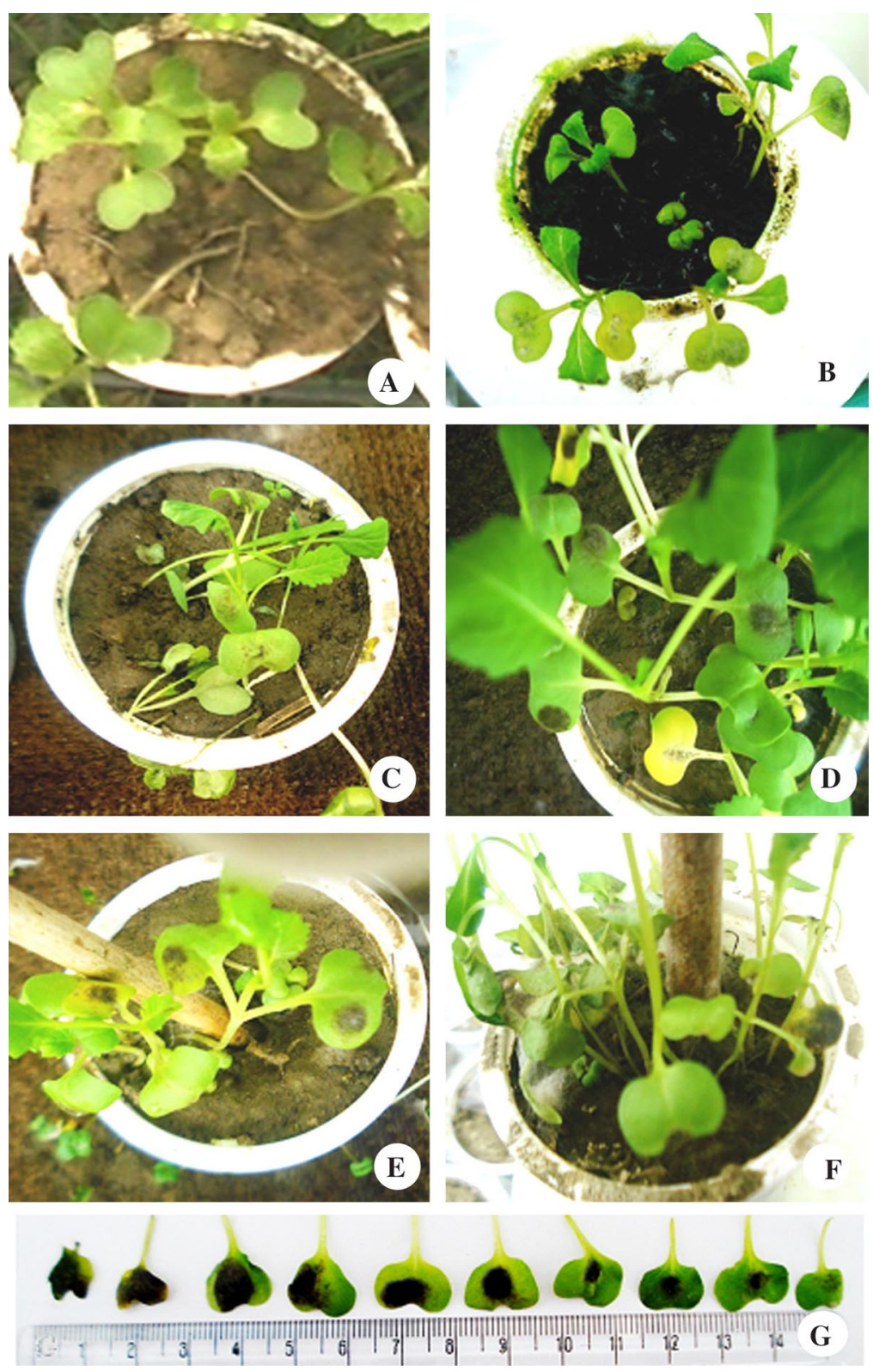

Fig. 1. Resistance test on cotyledon in mustard germplasm against Sclerotinia sclerotiorum: A. Resistant; B-C. Moderately resistant; D. Moderately susceptible; E. Susceptible; F. Highly susceptible and G. Different lesion on cotyledons of mustard.

were susceptible and 1 found highly susceptible. Out of 5 germplasm of Brassica sp. 2 were susceptible, 2 were moderately susceptible, and 1 was highly susceptible against S. sclerotiorum. S. sclerotiorum. These results support the findings of Nooshin and Dalili(13) 
and $\mathrm{Li}$ et al.(14). Results of in vitro germplasm evaluation showed that, none of the rapeseed mustard genotypes tested was immune against $S$. sclerotiorum. Bradley et al. (15) found significant differences between canola genotypes but there were absence of complete resistance against S. sclerotiorum genotypes. Garg et al.(8) evaluated cotyledon and field screening of several B. napus genotypes for their reaction against $S$. sclerotiorum and found certain partial resistance genotypes of Brassica napus. Dalili et al.(16) evaluated 25 rapeseed genotypes against sclerotinia rot for two years and reported significant differences between the genotypes.

The results showed that out of 81 germplasm, only seven found resistant against sclerotinia stem rot disease of mustard in cotyledon assay. Among them 2 germplasm belonged to species of Brassica rapa, 3 were B. juncea and 2 were from B. napus. None of the cultivated varieties found resistant against Sclerotinia sclerotiorum in our country.

\section{Acknowledgements}

The first author (NN) gratefully acknowledges the financial assistance from the University Grant Commission for Ph. D. fellowship. The authors are also thankful to Dr. Shalimuddin Ahmed, Senior Scientific Officer, Plant Breeding Division, BARI, Gazipur, Bangladesh for providing greenhouse facilities.

\section{References}

1. Boland GJ and R Hall 1994. Index of plant hosts for Sclerotinia sclerotiorum. Can. J. Bot. 16: 93-108.

2. Hind TL, GJ Ash and GM Murray 2003. Prevalence of Sclerotinia stem rot of canola in New South Wales. Australian J. Experimental Agri. 43: 163-168.

3. Sprague S and S Stewart-Wade 2002. Sclerotinia in canola - results from petal and disease surveys across Victoria in 2001. In: Grains research and development corporation research update-southern region, Australia. Grains Research and Development Corporation, Victoria, $78 \mathrm{pp}$.

4. Koch S, S Dunker, B Kleinhenz, M Rohrig and A von Tiedemann 2007. A crop loss related forcasting model for Sclerotinia stem rot in winter oilseed rape. Phytopathology. 97: 11861194.

5. Bolton MD, BPHJ Thomma and BD Nelson 2006. Sclerotinia sclerotiorum (Lib.) de Bary: biology and molecular traits of a cosmopolitan pathogen. Molecular Plant Pathology 7: 1-16.

6. Bardin SD and HC Huang 2001. Research on biology and control of Sclerotinia disease in Canada. C. J. P. Pathol. 23: 88-98.

7. Zhao J, AJ Peltier, J Meng, TC Osborn and CR Grau 2004. Evaluation of Sclerotinia stem rot resistance in oilseed Brassica napus using a petiole inoculation technique under greenhouse conditions. Plant Disease 88: 1033-1039. 
8. Garg H, K Sivasithamparam, SS Banga and MJ Barbetti 2008. Cotyledon assay as a rapid and reliable method of screening for resistance against Sclerotinia sclerotiorum in Brassica napus genotypes. Aust. Plant Pathol. 37: 106-111.

9. Seguin-Swartz G and C Lefol 1999. Sclerotinia stem rot resistance in crucifers. In: Proceedings of $10^{\text {th }}$ International Rapeseed Congress, Canberra, Australia, The Regional Institute Ltd.

10. Kim HS, GL Hartman, JBManandhar, GL Graef, JR Steadman and BW Diers 2000. Reaction of soybean cultivars to Sclerotinia stem rot in field, greenhouse, and laboratory evaluations. Crop Sci. 40: 665-669.

11. Kull LS, TD Vuong, KS Powers, KM Eskridge, JR Steadman and GL Hartman 2003. Evaluation of resistance screening methods for Sclerotinia stem rot of soybean and dry bean. Plant Disease. 87: 1471-1476.

12. AICRIP $\mathrm{R}$ and $\mathrm{M}$ 2011. Revised rating scale of major diseases of rapeseed-mustard. Proceedings of 18th annual group meeting of AICRP rapeseed-mustard. Khanpur campus, AAU, Guwahati (Assam). p. 1.

13. Nooshin A and A Dalili 2014. Evaluation of resistance in rapeseed lines against Sclerotiniasp. (Sclerotinia sclerotiorum). Oilseed Brassica 5(1): 32-39.

14. Lie CX, SY Liu, K Sivasithamparam and MJ Barbetti 2009. New sources of resistance to Sclerotinia stem rot caused by Sclerotinia sclerotiorumin Chinese and Australian Brassica napus and B. juncea germplasm screened under Western Australian conditions, Aust Plant Pathol. 38: 149-152.

15. Bradley CA, RA Henson,PM Porter, DG LeGare, LE del Rio and SD Khot 2006. Response of canola cultivars to Sclerotinia sclerotiorum in controlled and field environments. Plant Disease 90: 215-219.

16. Dalili SA, SV Alavi and G Arab 2004. Evaluation of relative resistance of rapeseed cultivars and lines to sclerotinia stem rot and isolation of the causal agent. Seed and Plant Improv. J. 20: 225-234. 